\title{
Associations between mental health symptoms in Palestinian captives' wives and in their children
}

\author{
Amer Shehadeh ${ }^{1,2 *}$, Ilse Derluyn ${ }^{3}$, Johan Vanderfaeillie ${ }^{4}$, Wolfgang Jacquet ${ }^{5}$ and Gerrit Loots ${ }^{1,6}$ \\ ${ }^{1}$ Research group Interpersonal, Discursive and Narrative Studies (IDNS) \& Centre for Children in Vulnerable Situations (CCVS), Vrije Universiteit Brussel, \\ Belgium \\ ${ }^{2}$ Ministry of Education, Directorate of Education, Bethlehem, Palestine \\ ${ }^{3}$ Department of Social Welfare Studies \& Centre for Children in Vulnerable Situations, Ghent University, Belgium \\ ${ }^{4}$ Department of Clinical and Lifespan Psychology, Vrije Universiteit Brussel, Belgium \\ ${ }^{5}$ Vrije Universiteit Brussel, Belgium \\ ${ }^{6}$ Universidad CatólicaBoliviana "San Pablo" La Paz, Instituto de Investigaciones en CienciasdelCompartamiento (IICC), Departamento de Psicología, Bolivia
}

\begin{abstract}
Summary
Background: Since 1967, the Palestinian Occupied Territories are marked by a protracted political conflict. During this conflict, about one fifth of the Palestinians have been detained; one third is married. Although parental detention negatively impacts family member's psychological wellbeing, little is known about the associations between the mental health of mothers and adolescents psychological wellbeing. Therefore, this study aimed at investigating the relationship between mother's mental health and children's psychological wellbeing of home is having husbands/ fathers in Israeli prisons.

Method: 115 Palestinian wives and 115 of their adolescents aged (11-18) years old took part; of 183 families, the father/husband was incarcerated. Participants completed self-report questionnaires on mental health. For mothers the General Health Questionnaire 28 (GHQ 28) was used, for children the Strengths and Difficulties Questionnaire (SDQ), and the UCLA Post Traumatic Stress Disorder - Reaction Index was filled in by the two groups. Kentall Tau correlation analyses have been used.

Results: Little associations were found between the mental health problems of captives' wives with the psychological and behavioral problems of their children. Living in cities, the time the husband stays already in prison and the mother's age are moderating predictors to develop and to strengthen the relationship between mothers' and children's mental health.

Conclusion: Based on these findings, we can consider the imprisonment of father/husband as a possible traumatizing experience for their wives and children within a context of ongoing political conflict. Besides, the study delineates considerable implications for the support and care for these adolescents and mothers.
\end{abstract}

\section{Key practitioner message}

- The impact of parental detention on family members' mental health is known

- This study shows the correlations between mothers and children's mental health problems resulting from the impact of a man's incarceration within the context of an ongoing political conflict in the West Bank (part of POT)

- Hereby, witnessing the arrest of the father puts additional risk onto adolescents' mental health

- Besides the strive for ending armed conflicts worldwide, all organizations and key actors, both governmental and nongovernmental, need to pay attention to this group, through providing psychosocial support programs. This kind of treatment and programs should be directed to the family as unit rather than to family members and offering coping strategies to those families

\section{Introduction}

War situation and political conflict may lead to important mental health problems in parents and children. Above, significant associations were found between the mental health of parents' and their children in these contexts.Studies documented higher levels of behavioral problems in young children of depressed mothers who are living in contexts of armed conflicts [1-4]. Alsochildren seemto be affected by their parent's reactions to traumatic events and war situations; in a way they can be considered as a mirror to stress reactions of their parents' responses.Studies indicate that there is a risk of transferring trauma symptoms, such as fear and anxiety, from mothers to children, making these children more vulnerable to further develop mental health problems [4-7]. Onthe other hand, some studies suggested that sociodemographic characteristics, such as living conditions and housing

Correspondence to: Amer Shehadeh, Faculty of Psychology and Educational Sciences, Department of Clinical and Lifespan Psychology, Vrije Universiteit Brussel, Pleinlaan 2, B-1050 Brussel, Belgium, Tel: +32466145202/ +970599548102; E-mail: ashehade@vub.ac.be/amershehadeh2008@yahoo.com

Key words: mental health problems, war-affected families, detained men, Palestine Received: February 06, 2017; Accepted: February 18, 2017; Published: February 20, 2017 
situations in time of war, are the mainpredicting factors for the mental health of mothers and their children $[5,8]$.

Other studies indicated that also paternal incarceration may lead to a range of mental health problems in their wives, such as depression, anxiety and loneliness, and hereby influencing theirpaternal response to their children. The absence of the father may challenge mothers' parenting tasks, as, for example, shown in an earlier study of [9]. Studies also showed that children's responses to paternal incarceration influence their mothers' psychological wellbeing, especially when children feel depressed, hopeless, fearful, worried and doubtful [1012]. This situation seems to influence mothers' parenting style, by, for example, over-pampering their children, complying with all their demands. On the other hand, mothers may become so frustrated and exhausted that they start becoming harsh parents, no longer being to offer the children tenderness and compassion [13].

In a recent study on the impact of Israeli imprisonment of Palestinian fathers on the psychosocial wellbeing of their family members in West Bank, [14-16] found that paternal imprisonment had a significant impact on the psychological wellbeing of their children and wives. Significantly more children of captives reported symptoms of posttraumatic stress disorder (PTSD) and psychological and behavior problems, compared to Palestinian children without having fathers in Israeli prisons. Children of captives living in rural areas or refugee camps showed higher risks to develop PTSD symptoms and psychological and behavior problems. Also, children living in their extended family houses tended to have more psychological and behavioral problems and more PTSD symptoms. Also, Palestinian wives of captives mentioned more mental health and PTSD problems compared to women whose husbands were not in prison. The time in captivity increased the risk of suffering from symptoms of depression and anxiety in Palestinian women whose husbands were imprisoned.

Although most of the aforementioned studies investigated the impact of fathers' incarceration on family members separately, research hardly focused on the mutual impact of paternal incarceration onto children or wives [11,17-29]. In contrast to research into war situations, there are hardly studies published that have investigated possible associations between the impact of paternal detention on the psychological wellbeing of mothers and their children.

Based on these previous findings, the purpose of this study is to investigate the possible associations between the psychological wellbeing of mothers and their teenage children in Palestinian families of which the husbands are incarcerated within a context of occupation or political conflict such as the Israeli Palestinian conflict. We hereby also investigate the possible impact of different socio-demographic moderating variables, such as the housing and living situation of the families, and the time the father is detained.

\section{Methods}

\section{Context}

The incarceration of Palestinians within the Palestinian Occupied Territories (POT) lasted for more than one hundred years, since the Othman era, going through Britten mandate and till nowadays by the Israeli occupation [30-32]. More than one fifth of the Palestinian population (700,000-800,000 habitants) experienced detention for different periods, ranging from 18 days until everlasting, since 1967, the starting point of Israeli occupation [33,34]. The highestlevel of Palestinians affected by and suffering from the occupation and arresting was reached during the first (1987-1991) and the second (2000-2005) Palestinian Intifada [30,33-36]; in the nineties and the years of the second intifada, the annual detention rates have peaked at 20,000 to 30,000 . Palestine can be considered as the most imprisonment society in the world [30,37]. A Human Rights Report, published in 1991, compared the rates of incarceration between the US (usually the highest percentage of incarceration in the world) and the Palestinian Occupied Territories (POT). The report estimated that the rates of incarceration in the POT have been 750 per 100,000 inhabitants, compared to 300 per 100,000 in US in the same period [30]. More than one third of these captives are married and have children and wives behind bars [33]. At the beginning of 2012 (the starting point of this study), the number of Palestinian captives in Israeli prisons reached about $[4,5,33,34,38]$ Most (89\%) of them are from West Bank governorates, the others from the Gaza Strip and from East Jerusalem, as shown in table 1.

Capturing fathers within an ongoing political conflict is a specific situation, because of the circumstances of the arresting process and society's view of detainees and their families. The Palestinian family is characterized by a pyramidal hierarchical structure in which the father occupies the top of the pyramid playing a central role. He usually represents the head of the family who is responsible for ensuring its living expenditure, providing security and protection for his family members who are under his control. According to the Palestinian Central Bureau of Statistics [38] 90.7\% of Palestinian families are headed by men.

\section{Study sample}

This study is part of a larger research project on the psychological well-being of Palestinian family members ( 183 wives and 283 children) who experienced paternal imprisonment, compared to family members with non-paternal incarceration ( 177 wives and 209 children) within an ongoing political conflict (Palestine). The two samples were randomly selected from four governorates out of the eleven governorates of the West Bank. These four selected governorates contain 550 families of imprisoned fathers. By taking every third name of this list, we reached the number of 183 families. The comparison group (families who did not experience detention in their nuclear family) was sampled from the same governorates, in cooperation with the Palestinian Ministry of Education and the Ministry of Health. We received a list of schools, mostly for girls $(n=190)$ and a list of health centers $(n=20)$. From these lists, we randomly took each fifth school and each second health center, and asked all employees (mostly females) to participate in the research. Of the 1,300 employees, 1,100 were married, from which 1,000 completed the questionnaires. From those completed questionnaires, 177 had never been confronted with detention in their family.

For this study, we included the captives' children aged more than 11 years old who filled in the questionnaires by themselves. Furthermore, when than 11, we only included the eldest one. The final participant group consisted of one hundred fifteen wives and 115 adolescents (Table 2).

Table 1. Numbers of married Palestinian captives in 2012 and duration of sentence [33].

\begin{tabular}{|c|c|}
\hline Number of married prisoners $(\mathbf{n = 1 , 2 5 0})$ & Sentence (years) \\
\hline $\mathbf{6 5 0}$ & $0-9$ \\
\hline $\mathbf{3 5 5}$ & $10-20$ \\
\hline $\mathbf{8 3}$ & $21-29$ \\
\hline $\mathbf{1 7}$ & $30-39$ \\
\hline $\mathbf{3}$ & $40-49$ \\
\hline $\mathbf{1}$ & $60-69$ \\
\hline $\mathbf{1 8 6}$ & ever lasting \\
\hline
\end{tabular}




\section{Procedure}

The data were collected by the use of three self-report questionnaires (UCLA-PTSD-Reaction Index, filled in by mothers and adolescents separately; the SDQ, filled in by the adolescents only, and the GHQ28 , filled in by the mothers only). The data were gathered by the first author and a team of three female social workers trained in research methodology. They visited the families of incarcerated fathers/husbands at their homes, informed them about the research and its aims, were asked their consent to participate, and were invited to complete the questionnaires. The researcher remained present to support the respondents if needed. Referral for mental health support was available to all participants upon request. All data were fully anonymous.

\section{Measures}

Next to a socio-demographic questionnaire, investigating age, gender, living environment (urban, rural, refugee camp), housing situation (separated house, living in father's family house or in mother's family house) and the time the father/husband spent in prison, both mothers and their teenage children completed two self-report questionnaires. Before data collection, the use of the questionnaires was discussed in a group of seven experts from Palestinian universities to verify their suitability for the research aims and the participants involved.

The UCLA-PTSD-Reaction Index (UCLA-PTSD-RI) [39] is a self-report questionnaire measuring, based on the DSM-IV criteria, symptoms of posttraumatic stress disorder (PTSD). This questionnaire has versions for children, adolescents and parents, and has been widely

Table 2. Socio-demographic characteristics of mothers.

\begin{tabular}{|l|c|c|}
\hline \multicolumn{1}{|l|}{ Age } & Number & $\%$ \\
\hline $\mathbf{2 0 - 2 9}$ years & 23 & 20 \\
\hline $\mathbf{3 0 - 3 9}$ years & 43 & 37.4 \\
\hline $\mathbf{4 0 - 4 9}$ years & 27 & 23.5 \\
\hline$>\mathbf{5 0}$ years & 21 & 18.3 \\
\hline Living environment & & \\
\hline City & 37 & 32.2 \\
\hline Village & 40 & 34.8 \\
\hline Refugee camp & 38 & 33 \\
\hline Time spent in prison & 3 & 2.6 \\
\hline$<\mathbf{1}$ year & 39 & 33.9 \\
\hline $\mathbf{1 - 5}$ years & 73 & 63.5 \\
\hline$>\mathbf{5}$ years & & \\
\hline Housing situation & 23 & 20 \\
\hline With family-in-law & 7 & 6.1 \\
\hline With parents & & \\
\hline
\end{tabular}

Table 3. Prevalence of psychological symptoms in both groups .

\begin{tabular}{|l|c|c|c|c|c|} 
& \multicolumn{3}{|c|}{ Mothers } & M.D & Mean \\
\hline Total PTSD score & N & M.D & 18.19 & 102 \\
\hline Total general health score (GHQ-28) & 111 & 49.14 & 44.96 \\
\hline Somatic symptoms & 110 & 52.50 & 12.34 & \\
\hline Anxiety & 114 & 12.54 & 4.48 & \\
\hline Social dysfunction & 114 & 14.89 & 3.69 & \\
\hline Depression & 115 & 11.87 & 5.97 & \\
\hline Total SDQ score & 112 & 13.52 & 4.30 & \\
\hline
\end{tabular}

PTSD: Posttraumatic Stress Disorder as measured by the UCLA-PTSD Reaction Index Questionnaire

SDQ: Strengths and Difficulties Questionnaire

GHQ-28: General Health Questionnaire-28 used in research on PTSD in children and adolescents. 22 items are scored on a Likert-scale from 0 (never) to 4 (always). For this study, we used the adults' and the adolescents' version, both the translated Arabic versions, which are adapted to the Palestinian context, and with has been found to have a sufficient reliability and validity [40,41].

The Strength and Difficulties Questionnaire (SDQ) [42] is a widely used self-report questionnaire to assess youth's psychological wellbeing $[42,43]$. In this study, we used the Arabic translation of the SDQ adolescents' version, which has already been used in Palestine [44,45]. The questionnaire contains 25 items to be scored on a Likert-scale from 0 (not true) to 2 (certainly true), adding up to a total difficulties score.

The General Health Questionnaire-28 (GHQ-28) [46] was the second questionnaire the mothers completed. This self-report questionnaire measures psychological wellbeing and consists of 28 items, divided into four subscales (each 7 items): somatic symptoms, anxiety/insomnia, social dysfunction, and severe depression. Each item can be answered on a Likert scale from 0 (not at all) to 3 (more than usual) [47]. The general health questionnaire was translated into many languages, including Arabic [48], and already used in Palestinian context [49]. Cronbach's alpha was 0.97 in our sample.

\section{Statistical analysis} characteristics (Table 2). In previous studies Shehadeh et al. [1416] used logistic regression analyses to investigate the influence of having a husband/father in prison on his wife's wellbeing and on children's psychological and behavioral problems. In what follows, the associations between the mental health aspects of the mothers with the mental health problems of the children are investigated. The moderating role of the socio-demographic variables in the associations between the mental health of the mothers and their children's wellbeing was explored. Because of the non-normality of the distributions of the scores and the difficultiesencountered to model the relations using our model, conditional Kentall Tau correlation analyses has been used. All analyses were performed using SSPS (version 22).

\section{Results}

\section{Associations between the wellbeing of mothers and children}

Table 3 provides an overview of the scores of the two groups under study on the different self-report questionnaires.

Little associations were found between the mental health problems of captives' wives with the psychological and behavioral problems of their children; there was only a significant relationship between the mothers' anxiety symptoms (GHQ-28) and their adolescents' PTSD symptoms (UCLA-PTSD-RI) (Table 4).
Descriptive statistics has been used to present samples demographic 
Table 4. Associations between the psychological symptoms of mothers and children.

\begin{tabular}{|c|c|c|c|c|c|c|c|}
\hline & \multicolumn{7}{|c|}{ MOTHERS } \\
\hline & & PTSD & & & GHQ-28 & & \\
\hline & & Total score & Total score & Somatic & Anxiety & Social dysfunction & Depression \\
\hline \multirow[t]{2}{*}{ CHILDREN } & Total PTSD & .000 & -.048 & -.019 & $-.197 * *$ & .041 & .052 \\
\hline & Total SDQ & .075 & .062 & .063 & -.101 & .080 & .093 \\
\hline
\end{tabular}

Kendau Tau Rank Correlation Coefficient.** $\mathrm{p}<0.01$

PTSD: Posttraumatic Stress Disorder as measured by the UCLA-PTSD Reaction Index Questionnaire

SDQ: Strengths and Difficulties Questionnaire

GHX-28: General Health Questionnaire-28

Table 5. Impact of socio-demographic characteristics on the correlations between mothers'PTSD symptoms and adolescents' wellbeing.

\begin{tabular}{|c|c|c|c|c|c|c|c|c|c|c|c|c|c|}
\hline & \multicolumn{13}{|c|}{ PTSD symptoms in mothers } \\
\hline & \multicolumn{4}{|c|}{ Mother's age (years) } & \multicolumn{3}{|c|}{ Living environment } & \multicolumn{3}{|c|}{ Housing situation } & \multicolumn{3}{|c|}{ Time of husband in prison } \\
\hline & $20-29$ & $30-39$ & $40-49$ & $>50$ & City & Village & Camp & parents & family-in-law & separated & $<1$ year & $1-5$ year & $>5$ years \\
\hline $\begin{array}{l}\text { Total PTSD } \\
\text { adolescents }\end{array}$ & 0.072 & -0.089 & -0.254 & 0.194 & 0.059 & -0.055 & -0.069 & 0.556 & 0.150 & -0.030 & 0.000 & $0.257^{*}$ & -0.144 \\
\hline $\begin{array}{l}\text { Total SDQ } \\
\text { adolescents }\end{array}$ & -0.006 & 0.086 & 0.098 & $-0.460 *$ & 0.127 & -0019 & 0.138 & 0.137 & 0.324 & 0.016 & 0.000 & 0.146 & 0.068 \\
\hline
\end{tabular}

Kendau Tau Rank Correlation Coefficient. ${ }^{*} \mathrm{p}<.05$

PTSD: Posttraumatic Stress Disorder as measured by the UCLA-PTSD Reaction Index Questionnaire

SDQ: Strengths and Difficulties Questionnaire

Table 6. Impact of socio-demographic characteristics on correlations between mothers'general health problems and adolescents' wellbeing.

\begin{tabular}{|c|c|c|c|c|c|c|c|c|c|c|c|c|c|}
\hline & \multicolumn{13}{|c|}{ General health problems in mothers } \\
\hline & \multicolumn{4}{|c|}{ Mother's age } & \multicolumn{3}{|c|}{ Living situation } & \multicolumn{3}{|c|}{ Housing situation } & \multicolumn{3}{|c|}{ Time of husband in prison } \\
\hline & $20-29$ & $30-39$ & $40-49$ & $>50$ & city & Village & camp & parents & family-in-law & separated & $<1$ year & $1-5$ year & $>5$ years \\
\hline $\begin{array}{l}\text { Total PTSD } \\
\text { adolescents }\end{array}$ & -0.087 & -0.023 & -0.236 & -0.030 & $0.333^{*}$ & -0.221 & 0.036 & 0.108 & 0.042 & -0.115 & 0.000 & -0.042 & -0.079 \\
\hline $\begin{array}{l}\text { Total SDQ } \\
\text { adolescents }\end{array}$ & -0.185 & 0.055 & 0.150 & 0.000 & 0.137 & -0.119 & 0.119 & -0.053 & -0.143 & 0.063 & 0.000 & 0.069 & 0.055 \\
\hline
\end{tabular}

Kendau Tau Rank Correlation Coefficient. ${ }^{*} \mathrm{p}<.05$

PTSD: Posttraumatic Stress Disorder as measured by the UCLA-PTSD Reaction Index Questionnaire

SDQ: Strengths and Difficulties Questionnaire

GHQ-28: General health problems as measured by General Health Questionnaire-28

\section{Impact of socio-demographic characteristics on the correlations between mothers' symptoms and adolescents' wellbeing}

According to the demographic variables, living in urban areas was significantly associated with the relationship between the severity of mothers' total health problems scores (GHQ-28) and their adolescents' PTSD symptoms (UCLA-PTSD-RI) (table 6). On the other hand, a negative and significant association was found between the PTSD symptoms (UCLA-PTSD-RI) of mothers who were older than 50 and their children's psychological and behavioral problems (SDQ) (table 5). Furthermore, a positive and significant correlation was found between mothers' and their children's PTSD symptoms (UCLA-PTSD$\mathrm{RI}$ ) according to the time their husband/father spent in prison (Tables 5 aand 6).

\section{Discussion}

This study aimed to understand the relationship between mothers' and children's psychological problems when the husband/ father is detained in a context of an ongoing political conflict. Our findings indicate that the mental health of the mothers did not predict children's wellbeing. There were no significant correlations between mothers' mental health and PTSD symptoms on the one hand, and their children's PTSD symptoms and psychological and behavioral problems on the other hand. These findings are in contrast with studies that have been done in the context of war (see, e.g., [2,4-6,50,51]). One possible explanation for this unexpected finding might be the age of the children. Maternal wellbeing seems to have a greater impact on younger children who are more attached to their parents [52,53], compared to adolescent children. Adolescents are more independent, with a growing ability to adjust by themselves or to get support from their peers [8,54-57]. Besides, in Palestinian culture, mostly the oldest child takes the role of the father when he is absent. Another possible explanation might be connected to the typical family constellation in Palestine: the children in this sample are part of extended, large, and closed families, which increase the likelihood that the child's wellbeing is influenced by multiple adults, and that more familial and social support might be available, which may counter the impact of stressful events [58].

The significant and negative correlations between mothers' anxiety and their children's PTSD symptoms might be explained by the comment that some items of the PTSD questionnaire indicating high PTSD scores (e.g., I try to stay away from people, places, or things that make me remember what happened) refer to behavior that keeps the children away from violent confrontations with the Israeli army, reducing the anxiety of their mothers.

Living within urban places (Palestinian cities) seems to strengthen the relationship between mothers' and children's mental health problems, whereas, according to the housing situation, many 
Palestinian families who are living within refugee camps and rural places are living within poor conditions and densely populated homes [59]. These conditions direct those families more to fulfilling basic needs and probably to less consider mental wellbeing, which might be in contrast with families living in the city, which are often more highly educated and mostly employed. Moreover, the governmental and non-governmental centers are mostly located within cities Palestinian Central Bureau of Statistics [38], which might increase the families' involvement in mental health services, rendering them to be more aware of psychological and behavioral problems.

A small positive, but significant correlation was found between mothers' and children's PTSD symptoms according to the time the father spent in captivity. One possible hypothesis can be that these mothers and children are still recovering from the bad memories of the father's arrest and still cannot adjust their lives yet; above, they might suffer from increasing concerns about their future.

As mentioned previously, mothers of older ages suffered more from PTSD and this was negatively correlated with children's psychological and behavioral problems. This could also be understood because of the higher support these older adolescents receive from friends or other peers, which may positively impact their psychological and behavioral problems [60]. As mentioned earlier, older teenagers in Palestinian society are often expected to take over when needed the role of the household head (i.e., the father). This particular role, possibly associated with a higher sense of responsibility towards their family, may reduce the levels of psychological and behavioral problems in these older participants [60]. This may suggest that adolescents experience reduced feelings of helplessness compared to younger children in similar situations. Another hypothesis could be that the cultural context impacts a tendency to avoid the expression of feelings, which might have led to an underreport of symptoms [61].

\section{Implications}

The findings presented suggest that detention of fathers has tremendous health consequences for their spouses and children. Therefore, all organizations and key actors, both governmental and non-governmental, need to pay attention to this group, through providing psychosocial support programs. Further, where needed, specialized psychological interventions need to be provided [5,62], and it would be good to train mental health workers in the specific needs and situation of these family members. This kind of treatment and programs should be directed to the family as unit rather than to family members and offering coping strategies to those families [61].

\section{Limitations}

The findings need to be interpreted within the limitations of this study. Firstly, we only collected data from $9 \%$ of the whole sample of captives' families, and from only one part of the three parts of POT. As a consequence, future knowledge could be strengthened by collecting data from other regions (i.e., East Jerusalem and Gaza Strip). Furthermore, we only included children of older ages. Future research could be strengthened by including children of young ages in our study. Finally, using self-report measures could be strengthened through also incorporating other perspectives, such as other family members and teachers.

\section{Acknowledgements}

We thank all participants, especially the wives and children of captives, for their cooperation. Above, we thank the Palestinian research team for their help and cooperation.

\section{Study funding}

This work was financially supported by the framework of the Erasmus Mundus External Cooperation Window (EM ECW) under the terms of the Grant Agreement nr 2010-5000 - 001-001-EMA2.

\section{Conflicts of interest}

The author(s) have declared that they have no competing or potential conflicts of interest.

\section{Contributor ships}

AS was responsible for the data collection. All authors have equally contributed to the design of the study, the data analysis and writing up of the report. All authors have full access to all data, and approve the work submitted.

\section{References}

1. Bryce JW, Walker N, Ghorayeb F, Kanj M (1989) Life experiences, response styles and mental health among mothers and children in Beirut, Lebanon. Soc Sci Med 28: 685-695.[Crossref]

2. Hadi F, Llabre MM, Spitzer S (2006) Gulf War-related trauma and psychologica distress of Kuwaiti children and their mothers. J Trauma Stress 19: 653-662.[Crossref]

3. Thabet AA, Abed Y,Vostanis P (2001) Effects of trauma on the mental health of Palestinian children and mothers in Gaza Strip. Eastem Mediterr Healt J 7: 413-421. [Crossref]

4. Laor N, Wolmer L, Cohen DJ (2001) Mothers' functioning and children's symptoms 5 years after a SCUD missile attack. Am J Psychiatry 158: 1020-1026.[Crossref]

5. Dybdahl R (2001) Children and mothers in war: an outcome study of a psychosocial intervention program. Child Dev 72: 1214-1230.[Crossref]

6. Robertson CL, Duckett L (2007) Mothering during war and postwar in Bosnia. J Fam Nurs 13: 461-483.[Crossref]

7. Yule W, Udwin O (1991) Screening child survivors for post-traumatic stress disorders: experiences from the 'Jupiter' sinking. Br J ClinPsychol 30 : 131-138.[Crossref]

8. Thabet AA, Abu Tawahina A, El Sarraj E, Vostanis P (2008) Exposure to war trauma and PTSD among parents and children in the Gaza strip. Eur Child Adolesc Psychiatry 17: 191-199.[Crossref]

9. Daniel SW, Barrett CJ (1981) The needs of prisoners' wives: a challenge for the mental health professions. Community Ment Health J 17: 310-322.[Crossref]

10. Behravan H (2010) Insecurity feeling amongst Wives. Int J Innov Manag Technol 1: 168-173.

11. Miller KM (2006) The Impact of Parental Incarceration on Children: An Emerging Need for Effective Interventions. Child Adolesc Soc Work J 23: 472-486.

12. Sherman LW, Strang H, Angel C, Woods D, Barnes GC, et al. (2005) Effects of faceto-face restorative justice on victims of crime in four randomized, controlled trials. $J$ Exp Criminol 1: 367-395.

13. Rosenberg J, Brett R (2009) Children Need Dads Too: Children with Fathers in Prison

14. Shehadeh A, Loots G, Vanderfaeillie J, Derluyn I (2015) The Impact of Parental Detention on the Psychological Wellbeing of Palestinian Children. PLoS One 10: e0133347. [Crossref]

15. Shehadeh A, Loots G, Vanderfaeillie J, Derluyn I (2016) The association between parental imprisonment and the mental health of Palestinian adolescents. Child Adolesc Ment Health 21: 154-160.

16. Shehadeh A, Loots G, Vanderfaeillie J, Derluyn I (2016) The Impact of Men's Detention on the Psychological Wellbeing of Palestinian Women. Ment Health Fam Med 12: 200-204.

17. Al-Turkait FA, Ohaeri JU (2008) Post-traumatic stress disorder among wives of Kuwaiti veterans of the first Gulf War. J Anxiety Disord 22: 18-31.[Crossref]

18. Calhoun PS, Beckham JC, Bosworth HB (2002) Caregiver burden and psychological distress in partners of veterans with chronic posttraumatic stress disorder. $J$ Trauma Stress 15: 205-212.[Crossref] 
19. Codd H (2007) Prisoners' Families and Resettlement: A Critical Analysis. Howard J Crim Justice 46: 255-263.

20. Dekel R (2007) Posttraumatic distress and growth among wives of prisoners of war: the contribution of husbands' posttraumatic stress disorder and wives' own attachments. $A m$ J Orthopsychiatry 77: 419-426.[Crossref]

21. Ein-Dor T, Doron G, Solomon Z, Mikulincer M, Shaver PR. (2010) Together in pain: attachment-related dyadic processes and posttraumatic stress disorder. J Couns Psychol 57: 317-327. [Crossref]

22. Hairston CF (1998) The forgotten parent: understanding the forces that influence incarcerated fathers' relationships with their children. Child Welfare 77: 617-639. [Crossref]

23. Kinner SA, Alati R, Najman JM, Williams GM(2007) Do paternal arrest and imprisonment lead to child behaviour problems and substance use? A longitudinal analysis. J Child Psychol Psychiatry 48: 1148-1156.[Crossref]

24. Malone PS, Lansford JE, Castellino DR, Berlin LJ, Dodge KA, et al. (2004) Divorce and Child Behavior Problems: Applying Latent Change Score Models to Life Event Data. StructEquModeling11: 401-423.[Crossref]

25. Manguno-Mire G, Sautter F, Lyons J, Myers L, Perry D, et al. (2007) Psychological distress and burden among female partners of combat veterans with PTSD. J Nerv Men Dis 195: 144-151.[Crossref]

26. Murray J, Farrington DP(2005) Parental imprisonment: effects on boys' antisocial behaviour and delinquency through the life-course. J Child Psychol Psychiatry 46: 1269-1278.[Crossref]

27. Pfiffner LJ, McBurnett K, Rathouz PJ (2001) Father absence and familial antisocia characteristics. J Abnorm Child Psychol 29: 357-367.[Crossref]

28. Wilbur MB, Marani JE, Appugliese D, Woods R, Siegel JA, et al. (2007) Socioemotional effects of fathers' incarceration on low-income, urban, school-aged children. Pediatrics 120: e678-685.[Crossref]

29. Geller A, Garfinkel I, Cooper CE, Mincy RB (2009) Parental Incarceration and Child Wellbeing: Implications for Urban Families. Soc Sci Q 90: 1186-1202.[Crossref]

30. Bornstein A (2010) Palestinian prison ontologies. Dialect Anthropol 34: 459-472.

31. Nashif E (2008) Palestinian political prisoners: Identity and community. (Routledge; 270, Madison Avenue, Ny, 10016).

32. Swedenburg T (1995) Memories of revolt. (Univirsity of minnesota press).

33. The Ministry of Detainees and Ex-Detainees Affairs, 2012. Annual report.

34. B`Tselem (2012) The Israeli Information Center for Human Rights in the Occupied Territories.

35. Allen L (2008) Getting by the occupation: How violence became normal during the Second Palestinian Intifada. Cult Anthropol 23: 453-487.

36. Brym R, Araj B (2006) Suicide bombing as interaction: The case of the Second Intifada. Soc Forces 84: 1969-1986.

37. Ron J (2000) Savage Restraint: Israel, Palestine and the Dialectics of Legal Repression. Soc Probl 47: 445-472.

38. (2011) Palestinian Central Bureau of Statistics. [http://www.citypopulation.de/ Palestine.html].

39. Rodriguez ND, Steinberg A, Pynoos RS (1999) UCLA PTSD INDEX for DSM IV (Revision 1) Instrument Information: Child Version, Parent Version, Adolescent Version. UCLA Trauma Psychiatry Serv. Los Angel.

40. Abdeen Z, Qasrawi R, Nabil S, Shaheen M(2008) Psychological reactions to Israel occupation: Findings from the national study of school-based screening in Palestine. Int J Behav Dev 32: 290-297.

41. Pat-Horenczyk R, Qasrawi R, Lesack R, Haj-Yahia M, Peled O, et al. (2009) Posttraumatic Symptoms, Functional Impairment, and Coping among Adolescents on Both Sides of the Israeli-Palestinian Conflict: A Cross-Cultural Approach. Appl Psychol 58: 688-708

42. Goodman R, Scott S(1999) Comparing the Strengths and Difficulties Questionnaire and the Child Behavior Checklist: Is Small Beautiful? J Abnorm Child Psychol 27: 17-24.[Crossref]

43. Goodman R (1997) The Strengths and Difficulties Questionnaire: a research note. $J$ Child Psychol Psychiatry 38: 581-586.[Crossref]

44. Thabet AA, Stretch D, Vostanis P (2000) Child mental health problems in Arab children: application of the strengths and difficulties questionnaire. Int $J$ Soc Psychiatry 46: 266-280.[Crossref]

45. Thabet AM. Al Ghamdi H, Abdulla T, Elhelou MW, Vostanis P (2010) Attention deficithyperactivity symptoms among Palestinian children. East Mediterr Health J 16: 505 510.[Crossref]

46. Goldberg DP, Hillier VF (1979) A scaled version of the General Health Questionnaire. Psychol Med 9: 139-145.[Crossref]

47. Sterling M (2011) General Health Questionnaire - 28 (GHQ-28). J Physiother 57: 259 [Crossref]

48. Thabet AA (2005) Validity of the Arabic Version of the General Health Questionnaire in the Gaza Strip. Palest Med J.

49. Thabet AM, Tawahina AA, Sarraj EE, Henely D, Pelleick H, et al. (2013) Comorbidity of post traumatic stress disorder, attention deficit with hyperactivity, conduct, and oppositional defiant disorder in Palestinian children affected by war on Gaza. Health (N. Y.) 05:994,

50. Murthy RS, Lakshminarayana R (2006) Mental health consequences of war: a brief review of research findings. World Psychiatry 5: 25-30.[Crossref]

51. Thabet AA, Abed Y, Vostanis P (2001) Effect of trauma on the mental health of Palestinian children and mothers in the Gaza Strip. East. Mediterr Health J Rev 7 : 413-421.

52. John Bowlby (1969) Attachment and loss.

53. John Bowlby (1980) Attachment and Loss: Loss, Sadness and Depression.

54. Gewirtz A, Forgatch M, Wieling E (2008) Parenting practices as potential mechanisms for child adjustment following mass trauma. JMarital Fam Ther 34: 177-192.[Crossref]

55. Hay DF, Pawlby S, Sharp D, Asten P, Mills A, et al. (2001) Intellectual problems shown by 11 -year-old children whose mothers had postnatal depression. J Child Psychol Psychiatry 42: 871-889.[Crossref]

56. Kelley ML (1994) Military-Induced Separation in Relation to Maternal Adjustment and Children's Behaviors. Mil Psychol 6: 163-176.

57. Qouta S, Punamäki RL, El Sarraj E (2005) Mother-Child Expression of Psychological Distress in War Trauma. Clin Child Psychol Psychiatry 10: 135-156.

58. Galante R, Foa D (1986) An Epidemiological Study of Psychic Trauma and Treatment Effectiveness for Children after a Natural Disaster. J Am Acad Child Psychiatry 25 357-363.

59. Lavee Y, Ben-David A, Azaiza F (1997) Israeli and Palestinian families in the peace process: sources of stress and response patterns. Fam Process 36: 247-263.[Crossref]

60. Pierce PF, Vinokur AD, Buck CL (1998) Effects of War-Induced Maternal Separation on Children's Adjustment During the Gulf War and Two Years Later1. J Appl Soc Psychol 28: 1286-1311.

61. Kelley M (1994) Military induced separation in relation to maternal adjustment and children's behaviour. MilitaryPsychology 6: 163-176.

62. Ehntholt KA, Yule W (2006) Practitioner review: assessment and treatment of refugee children and adolescents who have experienced war-related trauma. $J$ Child Psychol Psychiatry 47: 1197-210. [Crossref]

Copyright: (C2017 Shehadeh A. This is an open-access article distributed under the terms of the Creative Commons Attribution License, which permits unrestricted use, distribution, and reproduction in any medium, provided the original author and source are credited. 